\title{
Oral biopsies: methods and applications
}

\author{
R. J. Oliver ${ }^{1}$ P. Sloan ${ }^{2}$ and M. N. Pemberton ${ }^{3}$
}

Biopsies are an important diagnostic tool for the diagnosis of lesions ranging from simple periapical lesions to malignancies. Planning prior to performing a biopsy is essential. It will be beneficial to the receiving pathologist in reaching a helpful and meaningful diagnosis, and therefore ultimately and more importantly, to the patient. This paper presents an updated view of biopsies and discusses some of the potential problems with biopsy technique and specimens and how to overcome them.

\begin{abstract}
A biopsy is often the only way to diagnose oral lesions and diseases and as with most procedures there is often more than one method of undertaking the surgery successfully. Whatever the method used, however, the aim is to provide a suitably representative sample for the pathologist to interpret, while minimising perioperative discomfort for the patient. An unsuitable, unrepresentative sample is of no use to the pathologist, clinician or most importantly the patient who would be ill served by an unnecessary repeat procedure. Although most biopsies are performed in hospitals, a recent study has shown that many general dental practitioners felt able to perform biopsies but lacked some of the necessary skills. ${ }^{1}$ The purpose of this article is to review those skills, to discuss new developments in this area, and to highlight some of the potential pitfalls that may occur in taking a biopsy and methods available to
\end{abstract}

${ }^{1}$ Lecturer in Oral Surgery, ${ }^{2}$ Professor of Oral Pathology, ${ }^{3}$ Consultant in Oral Medicine, Oral and Maxillofacial Sciences, University Dental Hospital of Manchester, Higher Cambridge Street, Manchester M156FH

Correspondence to: Dr. Richard Oliver, University Dental Hospital of Manchester, Higher Cambridge Street,

Manchester, M15 6FH

E-mail:richard.j.oliver@man.ac.uk

\section{Refereed Paper}

doi:10.1038/sj.bdj.4811075

Received 05.12.02; Accepted 07.07.03

๑ British Dental Journal 2004; 196: 329-333 avoid them. The authors feel it will be of value to both general dental practitioners and junior hospital staff. Problems related to specific areas will be covered including apical lesions and those associated with the dental hard tissues. Mucosal and soft tissue biopsies together with general points regarding techniques and fixation will also be discussed.

\section{SPECIFIC TISSUES}

Apical lesions and those associated with the dental hard tissues

Many apical lesions are submitted routinely from general dental practice as well as hospitals following periradicular surgery. The majority of the lesions are inflammatory in origin, most commonly periapical granulomas or radicular cysts. Less commonly, other odontogenic cysts present at the apex, namely nasopalatine duct cyst or of greater significance the odontogenic keratocyst. Less frequently still, odontogenic tumours may present at such a site. Bone lesions such as Langerhans cell histiocytosis, giant cell granuloma and myeloma may also present in this way. Rarely, malignant metastatic deposits or even intraosseous squamous cell carcinoma can occur at this site. ${ }^{2}$ The value of routinely examining apical lesions has recently been questioned, ${ }^{3}$ however, the resulting correspondence has all been strongly in support of submitting material; one respondent ${ }^{4}$ cited that the non-submission of material often leads to a failure to diagnose and the situation regarding periapical lesions is no different, no matter how rare such instances occur.

For diagnosis, the excised material needs to be fixed to stop tissue autolysis prior to the sample reaching the pathology laboratory. The solution of choice to do this is $10 \%$ neutral buffered formalin fixative (a $4 \%$ solution of formaldehyde). This can easily be obtained on request from most pathology laboratories together with a supply of request forms and specimen pots. In a recent survey, ${ }^{1}$ many practitioners appeared unaware of these facilities and as such pathology laboratories may need to consider advertising their services more widely. It should be noted that some laboratories might levy a nominal charge for such services.

Some clinicians submit apical lesions on gauze which has been placed in formalin solution. However, if the volume of formalin in the container is not great enough, the gauze tends to absorb most of the formalin leaving the specimen dry and unfixed. Although not essential, it is desirable to inform the pathologist if bone is included in the specimen.

Occasionally, it is necessary to examine the dental hard tissues, most often to rule out an abnormality of dentine or enamel. 
As with most other tissues submitted for routine examination, teeth should also be submitted in 10\% neutral buffered formalin fixative. A mineralised sample, such as bone or tooth may require decalcification before it can be processed. The time for the decalcification will vary according to the size and consistency of the specimen as well as the methods employed by a particular laboratory, but it should be borne in mind that it can be a matter of weeks before a histopathology report is available.

\section{Mucosal biopsies}

Biopsy technique for the sampling of mucosal biopsies can be critical. If a tumour or premalignant disease is suspected, or when widespread mucosal disease is suspected, we would strongly advocate the biopsy being undertaken in a hospital setting following appropriate referral; such lesions should not be biopsied in general dental practice. Such biopsies should be performed by the clinician who is going to initiate the treatment. Some of the following section is, therefore, for information for general dental practitioners and of more relevance to junior hospital staff.

Simple excisional biopsies of polyps or epulides are suitable for general dental practice, and can be both diagnostic and curative at the same time. Before embarking on a biopsy the question of what the biopsy is being taken for must be answered (Table 1). The provisional clinical diagnosis is especially important in guiding the technique and tissue handling to be used (Table 2).

\section{Suspected malignancy}

If the reason for the biopsy was to exclude malignancy in a long-standing ulcer, a biopsy of the ulcer to include some adjacent clinically normal epithelium would be desirable. If the lesion is a carcinoma this allows confirmation that it is arising from the overlying epithelium rather than from a deeper structure or from a metastasis from a different site. It also allows the invasive front to be examined which can yield useful prognostic information. ${ }^{5}$ The centre of larger tumours should be avoided as this is often necrotic and will not yield diagnostic material. A recent study has demonstrated that cytokeratins were present in the peripheral blood of two out of ten patients 15 minutes after the incisional biopsy of an oral squamous cell carcinoma, thereby demonstrating that there was dissemination of cancer cells which may result in metastasis. ${ }^{6}$ These authors suggested that chemotherapeutic drugs should be administered prior to biopsy to minimise the risk of metastasis in such patients. However, the incidence of blood borne metastasis in relation to oral cancer is low, but this area merits further investigation.

\section{Mucocutaneous lesions}

Biopsies are commonly taken to confirm the clinical diagnosis of lichen planus, lichenoid reactions or other similar mucocutaneous conditions. To aid in the histological diagnosis of such lesions, an area of non-erosive lesional tissue should be chosen. Sampling of an erosive area will often show non-specific inflammatory changes associated with ulceration and will not aid in the diagnosis. Adjacent normal tissue is not generally required for such lesions. Similarly for suspected vesiculobullous disorders, the site of the biopsy should be adjacent to bulla where the epithelium is still intact. For these lesions it is desirable also for the laboratory to receive a fresh specimen of tissue in addition to a formalin fixed one to allow direct immunofluorescence (see later regarding fresh specimens). When desquamative gingivitis is present, the biopsy should be taken from the most

Table 1 Points to consider prior to mucosal biopsy
1. Why is biopsy being taken? Eg to confirm a mucosal disease such as lichen
planus or to exclude malignancy.
2. What information is required from the pathologist? Eg is the lesion
completely excised.
3. Is the biopsy to exclude malignancy? Therefore take the biopsy from the edge
of the lesion
4. Is the biopsy incisional or excisional? Eg For excisional biopsies a margin of
surrounding normal tissue will be required.
5. Will the specimen be required to be orientated? This is important for excisional
biopsies so that if residual tumour is left or the excision is close to the
margin, the surgeon knows where to perform a re-excision if necessary.
6. Is a fresh specimen required? For vesiculobullous lesions these are often
required for direct immunofluorescence. They are also used if a rapid diagnosis
is required.

intact area of mucosa which is often the attached gingiva; an elliptical area of mucosa is incised and carefully dissected from the underlying periosteum with a Mitchell's trimmer.

\section{Precancerous lesions}

For the precancerous lesions of leukoplakia and erythroplakia, the adequate and correct sampling of lesions may prove more difficult. It is now well recognised that lesions showing a non-homogenous or speckled appearance and lesions of erythroplakia are potentially more serious with a generally higher incidence of dysplasia and malignant transformation. ${ }^{7}$ These areas, if present, should be the site of choice for biopsy. If the lesion is extensive or there are numerous erythematous regions it may be prudent to biopsy more than one area.

\section{Handling of mucosal biopsies}

Care should be exercised when handling mucosal biopsy specimens as they can be particularly prone to damage. Sometimes specimens can be rendered of little diagnostic value due to poor handling which produce a crush artefact in histological section. There are various methods available to reduce traumatic damage to the specimens.

A popular method is to place a suture within the mucosa that is to be removed, and hold the ends of the suture in an artery forcep or sometimes tie a loose knot above the mucosa, while undertaking the biopsy. A tight knot close to the specimen, however, is to be avoided as it may result in the tissue being crushed. The use of such a suture can aid the biopsy procedure by providing traction and preventing unwanted movement of tissue when taking a biopsy from mobile structures such as the tongue. It also helps the pathologist to orientate the biopsy sample for sectioning. The 'traditional' technique using toothed tissue forceps to grasp the specimen is acceptable providing care is taken and the area grasped is away from the main site of interest.

The punch biopsy technique is an alternative to the traditional incisional biopsy. ${ }^{8}$ Essentially the punch comprises a circular blade attached to a plastic handle. Diameters of two to ten millimetres are available. This removes a core of tissue the base of which can be simply and atraumatically released using curved scissors. Alternatively, the specimen can be lifted from the mucosal surface and the base undermined with a scalpel. Care should be taken if aspiration is being used to prevent the specimen being sucked away. The resultant wound may not require suturing if using the smaller diameter punches. This technique is described and reviewed in detail by 
Table 2 Guidelines for an appropriate biopsy

\begin{tabular}{|c|c|c|}
\hline Clinical diagnosis & Type of biopsy & $\begin{array}{l}\text { Suitable for general } \\
\text { dental practice }\end{array}$ \\
\hline $\begin{array}{l}\text { Chronic ulcer or } \\
\text { squamous cell carcinoma }\end{array}$ & $\begin{array}{l}\text { Incisional biopsy of } \\
\text { margin of ulcer }\end{array}$ & $\begin{array}{l}\text { No, urgent referral } \\
\text { to hospital }\end{array}$ \\
\hline Leukoplakia/erythroplakia & $\begin{array}{l}\text { Incisional or punch } \\
\text { biopsy of worst area } \\
\text { consider multiple } \\
\text { biopsies if extensive } \\
\text { lesion }\end{array}$ & No, referral to hospital \\
\hline Mucosal lichen planus & $\begin{array}{l}\text { Incisional biopsy of a } \\
\text { representative area }\end{array}$ & $\begin{array}{l}\text { Only very experienced } \\
\text { practitioners }\end{array}$ \\
\hline $\begin{array}{l}\text { Bullous lesions } \\
\text { (pemphigus pemphigoid, } \\
\text { etc) }\end{array}$ & $\begin{array}{l}\text { Incisional or punch } \\
\text { biopsy of unaffected } \\
\text { mucosa close to bulla or } \\
\text { erosion plus fresh tissue } \\
\text { specimen }\end{array}$ & No, referral to hospital \\
\hline $\begin{array}{l}\text { Granulomatous diseases } \\
\text { (Crohn's, orofacial } \\
\text { granulomatosis, } \\
\text { ulcerative colitis, TB) }\end{array}$ & $\begin{array}{l}\text { Deep incisional biopsy } \\
\text { plus fresh sample to } \\
\text { microbiology if infective } \\
\text { agent suspected }\end{array}$ & No, referral to hospital \\
\hline Mucocoele & Careful excision biopsy & Yes, with care \\
\hline $\begin{array}{l}\text { Fibroepithelial polyp, } \\
\text { pyogenic granuloma, } \\
\text { epulis }\end{array}$ & Excision biopsy & Yes \\
\hline $\begin{array}{l}\text { Minor salivary gland } \\
\text { tumour }\end{array}$ & $\begin{array}{l}\text { Palate: deep incisional } \\
\text { biopsy } \\
\text { Upper lip: excisional } \\
\text { biopsy }\end{array}$ & $\begin{array}{l}\text { No, urgent referral } \\
\text { to hospital }\end{array}$ \\
\hline $\begin{array}{l}\text { Major salivary gland } \\
\text { tumour }\end{array}$ & $\begin{array}{l}\text { FNAC/FNCB (Seek } \\
\text { advice) }\end{array}$ & $\begin{array}{l}\text { No, urgent referral } \\
\text { to hospital }\end{array}$ \\
\hline
\end{tabular}

Lynch and Morris. ${ }^{9}$ Punch biopsies have been shown to have fewer artefacts than conventional incisional biopsies, ${ }^{10}$ although Kerwala $^{11}$ argued that careful handling using a suture during an incisional biopsy would also produce minimal artefacts. A case has been reported of surgical emphysema following an intra-oral punch biopsy caused by the patient sneezing shortly after the procedure. ${ }^{12}$ The use of punch biopsies does require the receiving laboratory to be familiar with the handling of such specimens. If in doubt, contact the laboratory prior to performing the biopsy. Also, it is generally safer to use the larger diameter punches to avoid handling problems both clinically and in the laboratory. This is especially true when material for both formalin-fixed and frozen processing is required, such as in the diagnosis of vesiculobullous disorders.

Generally when performing a mucosal biopsy an adequate depth of tissue should be obtained to include the epithelium and a few millimetres of underlying lamina propria. Traditional incisional biopsies are in the shape of an ellipse, the length of which should be approximately three times the width. ${ }^{13}$

The site of the biopsy may determine which of the above techniques are possible. For example, palatal and gingival sites do not generally allow adequate biopsies using the punch biopsy technique, and access to some sites such as the lingual gingivae may be impossible using this technique.

\section{Orientation of biopsies}

The majority of mucosal biopsies are incisional, however, occasionally small lesions may be excised encompassing diagnosis and treatment in one operation. If malignancy is suspected, the biopsy should be of sufficient depth and have a surrounding margin to ensure adequate clearance. In case the lesion was not completely excised it should be orientated. This can be achieved by placing a suture at one known margin, for example the anterior or superior margin. This would enable the pathologist to confidently indicate the precise location of any residual tumour. The same applies for surgical resection specimens.

A technique new to the oral cavity but established for other bodily sites is that of the brush biopsy. Essentially a hybrid of fine needle aspiration biopsy and exfoliative cytology, this technique uses a small brush to sample cells from all the layers of the epithelium. Only one large study from the United States has yet been published but they claimed a high sensitivity and specificity using the technique to detect dysplasia. ${ }^{14}$

\section{SOFT TISSUE BIOPSIES}

Biopsies of the soft tissues are a less common procedure. Indications include the diagnosis of granulomatous conditions such as Crohn's disease and the diagnosis of salivary lesions. In the case of the former, an incisional biopsy of adequate depth is required. Punch biopsies can sometimes be used but their depth of penetration is often limited.

When performing labial gland biopsies in the diagnosis of Sjögren's syndrome, a minimum of five minor salivary gland lobules should be obtained. The lower lip is the site of choice and care should be taken to minimise trauma to adjacent glandular tissue which is not being removed. Additionally, minimal sharp dissection of the area should be performed to lessen the chance of sensory nerve damage.

Mucocoeles arise from the blockage and subsequent rupture of minor salivary gland ducts. It is important when excising such lesions to remove the associated minor salivary glands to help prevent recurrence. As with labial gland biopsies, care should be exercised to minimise trauma to adjacent tissues. Mucocoeles are extremely uncommon in the upper lip, so swellings in this site should be treated as minor salivary gland tumours, until proved otherwise, and carefully and completely excised.

For palatal swellings which are suspected salivary tumours, incisional biopsies should be as deep as possible and down to bone if appropriate after due attention to the position of the palatal vessels and nerves. This is due to the anatomy of the region as lesions can be a considerable depth beneath the mucosa and so a superficial biopsy may give a false negative result.

Vascular lesions, haemangiomas for example, should be approached with caution. Incisional biopsies should never be performed. Smaller lesions obviously within the soft tissues can safely be excised. Larger lesions, particularly those affecting the lip are best ablated with either laser or cryosurgery. The disadvantage of these techniques is the lack of material for histological examination.

For the diagnosis of extra-oral soft tissue swellings the techniques of fine needle aspiration cytology (FNAC) and fine needle cutting biopsy (FNCB) are advocated in certain situations. These techniques are specialised and the reader is directed towards other publications for details of FNAC $^{15}$ and FNCB $^{16}$ techniques. The former is often best performed by or under the guidance of an experienced cytologist.

\section{FIXATION AND TRANSPORT}

Ensure the specimen is placed in an adequate volume of fixative, this should be at least ten times the volume of the specimen. Avoid the use of gauze to place the speci- 


Table $\mathbf{3}$ Information to accompany mucosal biopsies
1. Patient demographic data
2. Description of the clinical appearance of the lesion and suspected diagnosis
3. The site of the biopsy
4. The relationship of the lesion to restorations, particularly amalgam
5. A detailed drug history
6. Medical history including blood dyscrasias
7. Smoking and alcohol consumption

men onto as it merely absorbs the fixative and can make separation of the specimen from the gauze difficult. The fixative should be $10 \%$ neutral buffered formalin which has a pungent and distinct odour. Occasionally, formalin is further diluted with water by ancillary staff or specimens are placed in alternative solutions such as saline or water which results in poor fixation and artefactual change. Formalin fixes specimens by forming intermolecular bridges between proteins and cross-links between protein end-groups. ${ }^{17}$ If this process does not occur, soon after removal from the body the specimen will undergo autolysis rendering the tissues progressively undecipherable histologically.

A disadvantage of the protein cross-linking produced by formalin is that the specimen is rendered unsuitable for immunofluorescent antibody staining. The diagnosis of vesiculobullous autoimmune disorders is aided by direct immunofluorescence of perilesional tissue which requires fresh material that can be immediately frozen. Most other immunohistochemical methods used in diagnosis can now be performed on fixed tissue with the use of antigen retrieval. ${ }^{18}$ The other main situation where fresh tissue is processed is when frozen sections are used to examine surgical margins perioperatively. Again the specimen should be delivered to the laboratory fresh in a sterile universal container or petri-dish. Prior to taking the specimen at operation, it is both advisable and courteous to telephone the laboratory to ensure technical support and a pathologist are available.

Sometimes it is necessary to send pathological specimens through the post to the laboratory. Both the tissue and the formalin in which it is placed are potentially harmful to those handling the specimen. Precise details of the regulations governing the posting of pathological specimens will be available from the laboratory or the Post Office. Most of the regulations are common sense and apply to the packaging of the specimen. The primary container in which the specimen is placed with the formalin should be tightly sealed and wrapped in sufficient absorbent material to absorb the fixative if leakage occurs. Paper towels or cotton wool are suitable for this purpose. The wrapped container should then be placed in a sealed plastic bag which should then be placed in a rigid outer container which is capable of being secured by adhesive tape. Specific cardboard boxes with full-depth lids or grooved polystyrene containers are available for this purpose. A further outer padded bag is recommended which should be labelled 'PATHOLOGICAL SPECIMEN - FRAGILE WITH CARE' and the name and address of the sender should be clearly displayed. Recent correspondence in this journal has highlighted the fact that oral pathology services do not get any part of the fee paid to the GDP for the biopsy. ${ }^{19}$

Occasionally, specimens are required for electron microscopy, these should ideally be fixed in glutaraldehyde, but formalin is an acceptable alternative; again this will require some pre-arrangement. Specimens for cytogenetics may be required to confirm genetic changes in rare tumours (for example, synovial sarcoma), these should be submitted in universal transport medium which has been stored at $4^{\circ} \mathrm{C}$.

\section{GENERAL POINTS}

Local anaesthesia should be administered deep to or in a field around the proposed biopsy site. A regional block can also be used although the haemostatic effect of the adrenaline within the anaesthetic solution will be lost. Sampling of tissues at the site of the local anaesthetic will produce artefactual tissue oedema or distortion. For example bulla formation in gingival tissue or oedema which may lead to confusion in the diagnosis of Crohn's disease or orofacial granulomatosis where interstitial oedema is one of the diagnostic features.

The biopsy should be planned before local anaesthetic is administered. Major vessels and nerves should be avoided and to minimise the risk of damage to smaller structures, incisions should be made parallel to their expected position. For example, in the palate, incisions should run parallel to the palatal nerves (ie antero-posteriorly) rather than across the nerves (medio-laterally).

Attention to the surgical technique will minimise the introduction of artefacts into the tissues which can hinder pathological diagnosis or even render the specimen non-diagnostic. Some such artefacts have been mentioned above and others are detailed elsewhere. ${ }^{20}$ Fulguration artefact is an important problem induced during electrosurgical or laser cutting of tissue. The resulting effect of a layer of carbonised tissue, a zone of thermal necrosis and a zone of tissue exhibiting thermal damage makes histopathological interpretation more difficult. ${ }^{21}$ As such these methods of cutting should not be used for diagnostic incisional biopsies.

Consideration should also be given to healing of the biopsy site. It has been suggested that punch biopsies can be left unsutured. ${ }^{9}$ Conventional incisional biopsies are usually closed. The traditional use of silk is now being replaced by resorbable sutures such as polyglactin, formulations of which exist which resorb more rapidly (Vicryl ${ }^{\circledR}$ Rapide, Ethicon Ltd, Edinburgh). The supply of catgut (manufactured from bovine intestine) sutures for human use in the UK has recently ceased because there are acceptable synthetic alternatives available although there is no evidence that there is any risk to human health. ${ }^{22} \mathrm{~A}$ noneugenol-containing periodontal dressing (Coe-PakTM, GC America Inc.) can be used for covering gingival biopsy sites. Where large palatal biopsies are planned, the securing of a periodontal dressing underneath a denture or pre-constructed acrylic base plate can be helpful.

Label the specimen container with the patient's name, date of birth, date of biopsy and the site of the biopsy together with the hospital number if appropriate. The site of the biopsy is especially important if there are specimens from more than one site in an individual patient. If more than one specimen has to be placed in the same container, they must be clearly marked, which is most readily done by means of sutures; do not rely on describing the shapes of the pieces of tissue submitted because when they are fixed this will probably have altered. For mucosal disease it is desirable for the pathologist to know details of the factors outlined in Table 3. Accompanying information such as this will enable a more comprehensive interpretation of the specimen, in turn, producing a more meaningful and useful report to the clinician.

Adequate clinical history supplied on the request form relevant to the suspected diagnosis is essential to enable the pathologist to provide a useful and meaningful diagnosis. Additionally, on the request form, it is desirable to have previous biopsy numbers to enable comparison to be made if necessary. For example, to comment on the progression or regression of a dysplastic lesion.

It is advised that all patients give informed written consent to having a biopsy as it is an unusual procedure for 
patients particularly in general dental practice (Dental Protection, personal communication). It would be appropriate to include on the consent form the indication for the biopsy and details of possible risks involved with biopsy procedures. These risks are mostly site related; paraesthesia can be induced in the lips or the tongue, swelling and bruising can result from procedures in the tongue, lips and buccal mucosa, and procedures in the floor of the mouth can lead to submandibular or sublingual duct damage. Removal of mucocoeles from the lip carries the risk of further gland damage and 'recurrence'. Kearns et al. ${ }^{23}$ reported a recent study into pain experience following oral mucosal biopsies. They concluded that most patients did not experience significant pain post-operatively and those that did were controlled adequately with analgesics; most patients' pain reduced after 3 days. It is important to give the standard post-operative oral surgery instructions to the patient.

\section{CONCLUSIONS}

When considering biopsy a little forward planning and thought can greatly improve the diagnostic value obtained. Careful handling of the tissue and prompt appropriate fixation will enable a confi- dent histological diagnosis to be reached. Inadequate care at any stage could result in a non-diagnostic biopsy and may necessitate the patient having a repeat procedure with its ensuing physical and psychological morbidity.

1. Diamanti N, Duxbury A J, Ariyaratnam S, Macfarlane T $V$. Attitudes to biopsy procedures in general dental practice. Br Dent J2002; 192: 588-592.

2. Lavery K, Blomquist J E, Awty M D, Stevens P J. Squamous cell carcinoma arising in a dental cyst. $\mathrm{Br}$ Dent J 1987: 162: 259-260.

3. Walton R E. Routine histopathologic examination of endodontic periradicular surgical specimens-is it warranted. Oral Surg Oral Med Oral Pathol Oral Radiol Endod 1998: 86: 505

4. Baughman R A. To biopsy or not. (Letter). Oral Surg Oral Med Oral Pathol Oral Radiol Endod 1999; 87: 644-645.

5. Bànkfalvi A, Piffko J. Prognostic and predictive factors in oral cancer: the role of the invasive tumour front. J Oral Pathol Med 2000; 29: 291-298.

6. Kinsukawa J, Suefuji Y, Ryu F, Noguchi R, I wamoto O, Kameyama T. Dissemination of cancer cells into circulation occurs by incisional biopsy of oral squamous cell carcinoma. J Oral Pathol Med 2000; 29: 303-307.

7. Speight P M, Morgan P R. The natural history and pathology of oral cancer and precancer. Comm Dent Health 1993; 10 (Suppl 1): 31-41.

8. Eisen D. The oral mucosal punch biopsy. Report of 140 cases. Arch Dermatol 1992; 128: 815-817.

9. Lynch D P, Morris L F. The mucosal punch biopsy: indications and technique. J Am Dent Assoc 1990; 121: 145-149.

10. Moule I, Parsons P A, Irvine G H. Avoiding artefacts in oral biopsies: the punch biopsy versus the incisional biopsy. Br J Oral Maxillofac Surg 1995; 33: 244-247.
11. Kerawala C J. Incisional biopsy: reducing artefact. Br J Oral Maxillofac Surg 1995; 33: 396.

12. Staines K, Felix D H. Surgical emphysema: an unusual complication of punch biopsy. Oral Diseases 1998; 4: 41-42.

13. Golden D P, Hooley J R. Oral mucosal biopsy procedures. Excisional and incisional. Dent Clin North Am 1994: 38: 279-300.

14. Sciubba J J. Improving detection of precancerous and cancerous oral lesions. Computer-assisted analysis of the oral brush biopsy. J Am Dent Assoc 1999; 130: 1445-1457.

15. Orell SR, Sterrett G F, Waters M N, Whitaker D. Manual and Atlas of Fine Needle Aspiration Cytology. Edinburgh and London: Churchill Livingstone, 1986

16. Southam J C, Bradley P F, Musgrove B T. Fine needle cutting biopsy of lesions of the head and neck. BrJ Oral Maxillofac Surg 1991; 29: 219-222.

17. Pearse A G E. The chemistry and practice of fixation. In Pearse A GE (Ed) Histochemistry. Theoretical and applied. Edinburgh: Churchill Livingstone, 1980: 97-158.

18. Shi SR, Cote R J, Taylor CR. Antigen retrieval immunohistochemistry: past, present, and future. J Histochem Cytochem 1997; 45: 327-343.

19. Odell E W, Morgan P R. Practitioner biopsy services. (Letter). Br Dent J 2002; 193: 182.

20. Margarone J E, Natiella J R, Vaughan C D. Artefacts in oral biopsy specimens. J Oral Maxillofac Surg 1985; 43: 163-172

21. Krause LS, Cobb C M, Rapley J W, Kilroy W J, Spencer P. Laser irradiation of bone. I. An in vitro study concerning the effects of the $\mathrm{CO} 2$ laser on oral mucosa and subadjacent bone. J Periodonto/ 1997; 68: 872-880.

22. Medical Devices Agency. Catgut sutures-cessation of supply. 2001. http://www.medical-devices.gov.UK/ catgutsutures.htm

23. Kearns H P O, McCartan B E, Lamey P-J. Patients' pain experience following oral mucosal biopsy under local anaesthesia. Br Dent J 2001; 190: 33-35. 